\title{
What Makes an Effective TESOL Teacher in the Gulf? An Empirical Exploration of Faculty-Student Perceptions for Context-Specific Teacher Preparation
}

\author{
Kashif Raza ${ }^{1}$ \\ Qatar University \\ Christine Coombe \\ Dubai Men's College, Higher Colleges of Technology
}

\begin{abstract}
Teacher education continues to remain an area of exploration and further development in contemporary research. One significant question that dominates discussions that focus on teacher development is "what makes them effective for their students?" Research on contextspecific teaching informs us that the metaphor "effective teacher" can be best described in light of the characteristics associated with the term in the context where this is being discussed and negotiated. Although the general list of qualities helps understand the dominant attributes of good teachers in the field, they do not always answer whether this makes a teacher successful in a specific context. To fill this gap, and to determine what teacher characteristics are valued the most in the Gulf context, the present study investigated faculty-student beliefs about the qualities of an effective English teacher using a mixed methods research design that utilized a bilingual survey to collect quantitative data from 66 teachers and 527 students, and individual interviews with 10 faculties and 14 students to further unpack the findings. This study reports that a teacher's ability to employ an efficient teaching methodology and develop a compassionate relationship with their students, regardless of their gender, age, nationality and accent, are the most preferred qualities of an effective English teacher in the Gulf. These findings are helpful for educators, policymakers, teacher trainers, education leaders, and researchers in employing, developing, and designing teacher-training programs in specific contexts.
\end{abstract}

Keywords: context-specific teaching, teaching English to Arab students, TESOL teacher preparation, TESOL in the Gulf.

Research into context-specific teaching (CST) suggests that teacher characteristics are perceived differently in different settings. A teacher characteristic that is seen as most favorable in one context can have a different preference in another. For example, a study by Sander et al. (2000) that surveyed undergraduate students at three British universities to understand their ranking of five given qualities of a good teacher found that the most preferred teacher quality was their teaching skills $(\mathrm{m}=2.94)$ followed by knowledge $(\mathrm{m}=2.29)$, approachableness $(\mathrm{m}=1.96)$, enthusiasm $(\mathrm{m}=1.88)$ and organization $(\mathrm{m}=0.89)$. In contrast, a survey study by McKnight et al.

${ }^{1}$ Corresponding Author E-Mail: kraza@qu.edu.qa 
(2016) that intended to explore the most valued qualities of an effective teacher across 23 countries concluded that five qualities were listed as highly preferred by students among which a teacher's ability to establish a good rapport was regarded as the most significant attribute. The other four qualities, according to their order of preference, were a patient, caring and kind personality, high level of professionalism, subject matter knowledge, and knowledge of learners. This shows that the most preferred quality in one context (e.g., Sander's study: teaching skills) can be the third most preferred quality in another context (e.g., McKnight's study: level of professionalism).

These differing responses to faculty attributes in different contexts highlight the significance of understanding context-specific teacher effectiveness, which can have an impact on teaching and learning, especially when a teacher's and their students' backgrounds are disparate. Many of these examples advocate for preparing teachers for CST by informing them of the expectations and the needs of the students and the program in the intended setting.

In addition to knowing the universal characteristics that increase teacher effectiveness in a classroom in general, an understanding of the context-specific qualities is also important. According to Klassen et al. (2018), "Perceptions of the most important personal characteristics of effective teachers are not universal, but vary according to national education expectations and the predominating cultural beliefs" (p. 72). The universal characteristics lists inform teachers of what is expected of them to become a good teacher in general, but they neither make them aware of what makes a teacher effective in a specific context, nor do they help meet the expectations and the perceptions of a specific population. For this, we need to understand the concept of teacher effectiveness in that specific context; this is what our study aims to achieve.

This study intends to investigate the teacher characteristics that enhance their effectiveness in an EFL classroom by collecting data from the students and the faculty in a foundation English program based in a Gulf country. More specifically, the study aims to find answers to the following research questions:

1) What teacher qualities are valued the most by the faculty and Gulf Arab students?

2) What are the differences and the similarities in the expectations of Gulf Arab students and the faculty about teacher qualities?

3) If there are differences between the expectations, how do these differences affect learning?

The results of the study will allow existing and newly hired English teachers to use the findings to prepare themselves for their students' expectations and needs, especially in the Gulf context. Another significant aspect of this study is that it provides baseline data to researchers interested in conducting similar research in the Gulf, more specifically, and in other parts of the world, in general, to develop an understanding of the characteristics that define an effective teacher in their context.

\section{Theoretical Framework}

The importance of context-specific teaching (CST) and preparing educators in this area is widely acknowledged. Borg (2006) argues for the need to investigate ways in which a teacher's characteristics are perceived in a specific context and suggests that in preparation for different contexts, language teachers and teacher trainers should be made aware of these expectations. In addition, Klassen et al. (2018) argue that context shapes the way a teacher's non-cognitive characteristics are perceived and propose developing teacher selection tools that are based upon 
the importance associated by a culture to specific attributes. Similarly, Borg (2018) recommends conducting case studies that can help administrators design evaluation criteria to assess English language teachers in specific contexts.

In addition, Sander et al. (2000) discuss the importance of investigating student priorities for teacher characteristics, and state that in doing so will, first, help manage students' impractical or unfitting expectations and, secondly, provide the opportunity for educators and school management to offer productive educational facilities that are guided by an understanding of the students' opinions. Likewise, Darling-Hammond and Snyder (2000) suggest continuous and planned teacher development that is guided by both an understanding of the learner context and existing literature on teaching and learning.

Research suggests different ways to increase cultural awareness as well as to integrate into the host culture (Douglas \& Rosvold, 2018; Raza, 2018, 2020). This activity not only helps meet the expectations of the students and the administrators but also promotes a healthy learning environment. A lot of research has been done on ways to acculturate educators to the host culture and society. Table 1 lists some of the suggestions made by the researchers to help teachers inform themselves about and familiarize themselves with the students' culture and adapt their teaching strategies to student needs and expectations.

\section{Table 1}

Summary of Suggestions for Successful Culturally Responsive Teaching

\begin{tabular}{ll}
\hline No. & \multicolumn{1}{c}{ Suggestion } \\
\hline 1 & Keeping a diary to reflect (Raza, 2018, 2020) \\
2 & Developing relationship with students (McKnight et al., 2016; Raza, 2019) \\
3 & Informed teacher judgments (Darling-Hammond \& Snyder, 2000) \\
4 & Investigate student perceptions of effective teacher characteristics (Borg, 2006; \\
& Coombe, 2013, 2020; Sander et al., 2000) \\
5 & Systematic cultural awareness training (Crabtree, 2010; Metropolitan Center for \\
& Urban Education, 2008; Weinstein et al., 2004) \\
6 & Peer mentoring - suggestions and tips from senior faculty (Anderson, 2004) \\
7 & Reading existing literature on the subject (Darling-Hammond \& Snyder, 2000; \\
& Weinstein et al., 2004) \\
9 & Teacher's transformative learning (Mezirow, 1978) \\
9 & Mutually adaptive learning paradigm (DeCapua et al., 2018) \\
10 & Teachers' self-assessment tools (Borg \& Edmett, 2019) \\
11 & Acquaintance of one's own cultural values, standards and preconceptions (Weinstein \\
& et al., 2004)
\end{tabular}

For instance, McKnight et al. (2016) conducted a survey study in 23 countries to understand which teacher qualities are considered the most valuable in these contexts. The purpose of the project was to collect data from multiple stakeholders, including students, teachers, administrators, policymakers, researchers, and parents, and use the data to educate teachers and inform future teacher development programs to address the local expectations. The study concluded, "across all participating countries the ability of the teacher to develop trusting, compassionate relationships with students was valued most" (p. 6). This was followed by compassion, professionalism, information related to the subject, and understanding of learners. 
Making the right decisions inside the classroom as well as outside are also significant in meeting learner expectations. Darling-Hammond and Snyder (2000) argue that successful language teaching involves effective teacher judgments that are informed by an understanding of the relationship between the targeted students' culture and their lifestyle. Reflective teaching is another option for cultural adaptation. Raza (2018) suggests keeping a teacher diary to note what works well in a specific classroom and develop teaching and classroom management skills based upon the notes. Another strategy to keep abreast of the changing classroom needs and student issues and preferences is the continuous study of the existing literature on the subject (Arslan \& Tanis, 2018; Darling-Hammond \& Snyder, 2000; Donohue, 2020).

Transformative learning, initially framed by Mezirow (1978), is another approach endorsed by many researchers (e.g., Adams, 2019; DeCapua et al., 2018; Raza, 2018, 2020) to readjust previously adapted teaching methodologies to target student needs and expectations. The process of transformation is gradual in nature and is informed by an understanding of the existing student perspectives, needs and beliefs about teaching and learning. Mutually Adaptive Learning Paradigm (MALP) is another similar approach coined by DeCapua and Marshall (2011). Originating from culturally responsive teaching, this approach aimed to bridge the gap between instructions given at school and the educational necessities of the unsuccessful students (Depua et al., 2018). Proponents of the approach believe that by challenging their own perceptions about learning and teaching, teachers can adapt their instruction to the existing culture and benefit students with limited or interrupted formal education (SLIFE).

Finally, yet importantly, students can also be a source of knowledge that can help develop cultural understanding and adapt to the contextual needs. Developing an understanding of the students' cultural values, their customs, lifestyles, and way of thinking can help us understand their expectations about a teacher's role in the classroom and about teaching and learning (Raza, 2018, 2020). This information helps in developing skills that can assist in intercultural communication (Weinstein et al., 2004). One significant way to utilize student knowledge is to collect information from them about their beliefs, expectations, and feelings. This is one of the objectives of the current study.

Students' feedback, which can either be formal (e.g., course evaluation) or informal (e.g., discussions) is an effective source of knowledge for educators. One significant way to utilize student knowledge and information for cultural orientation is to investigate their perceptions about teacher effectiveness and about teaching and learning. Since students know more about their culture compared to teachers and their perceptions are based upon their culture, values, traditions and customs, Sander et al. (2000) argue that addressing their expectations can produce better outcomes. In addition, this information can also be used to understand which teacher characteristics are perceived more importantly compared to others to adjust to student needs. Kourieos and Evripidou (2013) emphasize the significance of considering student perceptions to make informed decisions, which can help teachers in understanding their students' needs, the factors that can motivate their learners, and the strategies to foster student learning. Similarly, Rubie-Davies et al. (2010) emphasize the need to investigate student expectations about their teachers, and argue that in doing so can increase student motivation to learn by positively affecting their image of school. Building upon the existing literature in this area, the present study aims to investigate student perceptions in a foundations program at a Gulf university to understand the teacher characteristics that are valued the most by the students and suggest ways to align the gap in the expectations between the students and the teachers. 


\section{Teacher Role and Effectiveness}

The importance of language teachers in the successful delivery of English language courses, students' skills development, and program growth is widely recognized by researchers. However, there is one question that has been asked repeatedly in academia and still requires more investigation: What makes a good and effective (English) teacher (Coombe, 2020)? Different researchers have tried to answer this question in different ways, and many teacher evaluation frameworks have been suggested in this regard. However, this area still requires further investigation and review.

For instance, Borg (2018) argues that quality teaching affects student achievement and suggests using more than one source of proof to measure teaching quality. His proposed teacher evaluation framework consists of nine different strategies, which can help understand how effective a teacher is in the classroom. In addition, Gourneau (2005) believes that in order for a teacher to be effective and leave a long lasting imprint on his students, they should possess five attitudes: "demonstrate kindness, share responsibility, accept diversity, foster individual instruction, and encourage creativity" (p. 8). Similarly, Coombe (2020) shortlisted ten characteristics of an effective teacher after a comprehensive literature review on teacher effectiveness. These include passion for teaching, content knowledge, personal qualities (e.g., building rapport with students), with-it-ness (e.g., classroom organization, student motivation), instructional effectiveness, good communication skills, street-smarts (up to date knowledge), willingness to go to the extra mile (e.g., inspire students), continuous professional development, and having a social life outside the classroom. Additionally, Anderson (2004) states that effective teachers are consistent goal-achievers; these goals are either set by the teachers themselves or by other stakeholders.

Table 2 lists teacher characteristics reported by different researchers from different contexts. Although these teacher characteristics and many others like these inform teachers of what makes an effective teacher in general, they do not provide any information of what it would take to prove their effectiveness in a specific context (Alogali, 2018; Anderson, 2004; Borg, 2006; Klassen et al., 2018; Sander et al., 2000).

\section{Context of the Study}

English language is seen as an important element in educational, social, and economic development in the Gulf. It is, especially, necessary for employment in the private sector because of the preference for bilingual staff. However, the education policy towards the teaching and learning of English as a foreign language in the Gulf region has experienced different shifts in the past (Syed, 2003) and the struggle to create a balance between English and Arabic education continues until today.

In addition to issues like low motivation, unimpressive achievement, rote learning and memorization, and course failure and dropout in Gulf EFL classrooms, foreign educators' lack of understanding of the local culture, language, and social values is a serious issue (Syed, 2003). A lack of understanding of the host culture can be detrimental in several ways. For instance, Sonleitner and Khelifa (2005) present the challenges faced by Western-educated faculty in the UAE. They found that faculty experience serious nervousness and lack of confidence in material selection and presentation in the first few weeks of their semester because they do not want to be disrespectful to students' cultural values unintentionally by presenting content that is considered 
controversial. Some other challenges faced by the faculty because of cultural differences include lack of student motivation, student openness about their lack of understanding of the content in the presence of other students, rote learning, student complaint system, educational goals, student behavior, and their attempts to meet their faculty expectations instead of developing the targeted skills (Sonleitner \& Khelifa, 2005; Syed, 2003; Vural, 2019).

\section{Table 2}

\section{Teacher Characteristics}

\begin{tabular}{|c|c|c|c|}
\hline Researcher(s) & Research Type & Preference Type & $\begin{array}{l}\text { Study } \\
\text { Participant(s) }\end{array}$ \\
\hline $\begin{array}{l}\text { Sander et al. } \\
(2000)\end{array}$ & Survey study & $\begin{array}{l}\text { Teaching skills - Most preferred } \\
\text { Knowledge - Second most preferred }\end{array}$ & - \\
\hline Coombe (2020) & Literature review & $\begin{array}{ll}\text { 1. } & \text { Passionate } \\
\text { 2. } & \text { Knowledgeable } \\
\text { 3. } & \text { Personal qualities } \\
\text { 4. } & \text { With-it-ness } \\
\text { 5. } & \text { Instructional effectiveness } \\
\text { 6. } & \text { Communication skills } \\
\text { 7. } & \text { Street-smart } \\
\text { 8. } & \text { Inspirational } \\
\text { 9. } & \text { Professional development } \\
\text { 10. } & \text { Social }\end{array}$ & - \\
\hline $\operatorname{McBer}(2000)$ & $\begin{array}{l}\text { Classroom observation, } \\
\text { interviews, questionnaires, } \\
\text { focus groups, collection of } \\
\text { personal and school data, and } \\
\text { pupil progress data }\end{array}$ & $\begin{array}{l}\text { 1. Teaching skills } \\
\text { 2. Professional characteristics } \\
\text { 3. Classroom climate }\end{array}$ & $\begin{array}{l}\text { Faculty, Students, } \\
\text { School Data }\end{array}$ \\
\hline Gourneau (2005) & Student notes (Qualitative data) & $\begin{array}{l}\text { 1. Demonstrating Caring and Kindness } \\
\text { 2. Sharing Responsibility } \\
\text { 3. Sensitively Accepting Diversity } \\
\text { 4. Fostering Individualized Instruction } \\
\text { 5. Encouraging Creativity }\end{array}$ & Students only \\
\hline $\begin{array}{l}\text { Tatar \& Da'as } \\
(2012)\end{array}$ & Questionnaire & $\begin{array}{l}\text { 1. Help and assist students } \\
\text { 2. Serve as a personal example for students }\end{array}$ & Faculty only \\
\hline $\begin{array}{l}\text { Kourieos \& } \\
\text { Evripidou (2013) }\end{array}$ & $\begin{array}{l}\text { Questionnaire and focus group } \\
\text { interviews }\end{array}$ & $\begin{array}{l}\text { 1. Considers student needs } \\
\text { 2. Uses technology } \\
\text { 3. Encourages student engagement }\end{array}$ & Students only \\
\hline $\begin{array}{l}\text { McKnight et al. } \\
(2016)\end{array}$ & $\begin{array}{l}\text { Survey study } \quad \text { (Quantitative } \\
\text { data) }\end{array}$ & Relationship development with students & $\begin{array}{l}\text { Students, } \\
\text { Teachers, } \\
\text { Principles, } \\
\text { Education } \\
\text { Researchers, } \\
\text { Education } \\
\text { Policymakers, } \\
\text { Student Parents }\end{array}$ \\
\hline $\begin{array}{l}\text { Klassen et al. } \\
(2018)\end{array}$ & Comparative Case Study & $\begin{array}{l}\text { 1. Empathy and Communication } \\
\text { 2. Organization and Planning } \\
\text { 3. Resilience and Adaptability }\end{array}$ & Faculty only \\
\hline Anderson (2004) & Book chapter: literature review & 1. Goal achievers & \\
\hline
\end{tabular}


Cultural orientation and a sense of understanding of the local culture is specifically important for a country where the majority of the English language teachers are expatriates. For example, in the language program where the study was conducted, there are around 120 faculties that come from different cultural, linguistic, and social backgrounds. Although there is a considerable number of Arab faculty teaching in this department, they do not always share the same culture and history. Since expectations are mostly based upon cultural and social values (Raza, 2019), it is essential to investigate learner and faculty beliefs about the teacher qualities that exemplify a teacher as an effective educator in a classroom with students from a different culture. The current study aims to fill this gap by exploring Arab students' and faculty's expectations about the characteristics of an effective English teacher.

\section{Research Methodology}

\section{Data Collection and Interpretation}

The study followed an interpretivist paradigm (Glesne, 1999) for data collection. An interpretivist design sees the construction of social reality because of communication between the members of a society. A thorough investigation of the participant views is necessary to understand the construction of these realities. Following an interpretivist paradigm, this study collected data in two dissimilar stages. First, a bilingual (English and Arabic) survey was used to collect baseline data from the students and the faculty. Secondly, based upon the findings from stage 1, individual interviews were conducted with students and faculty to understand their perceptions of teacher qualities in more depth. The interpretivist design allowed the researchers to explore student and faculty perceptions of teacher qualities in detail.

\section{Participants}

Data were collected from the students and the faculty in a language program at a Gulf university for two consecutive semesters. The program, consisting of three sub-programs (Foundation, Post-Foundation, and Embedded), aims to prepare students for its client colleges (Engineering, Pharmacy, Social Sciences, Education, Sharia, Policy Development, Law, etc.) by developing their English language skills. The students in the program follow one of the two streams (English or Arabic) when they study their future majors: Foundation and Post-Foundation students take their majors in English and Embedded students study their majors in Arabic.

The Foundation Program consists of two semesters, offers non-credit courses, and accepts students that are not able to get 6.5 on the IELTS exam. To start Post-Foundation courses, students can either get the required IELTS score (6.5) or study in the Foundation Program for two semesters. The two Post-Foundation courses (ENGL202 and ENGL203) are writing extensive and students receive credits for completing them. On the other hand, all the students that are enrolled in Embedded courses must take 4 courses (ENGL110, ENGL111, ENGL250 and ENGL251). The English language proficiency level of the students varies from program to program or from course to course; however, depending upon their sub-program, they can be categorized as intermediate to advanced level students.

Since the study adapted a mixed methods research design, the data from the students and the faculty were collected in two distinct stages. First, quantitative data were collected from 66 
faculties and 527 students. Table 3 provides demographic information about the gender, nationality, and age of the faculty and the student participants.

\section{Table 3}

Quantitative Data Collection: Demographics

\begin{tabular}{|c|c|c|c|}
\hline Participants & Gender & Nationality & Age \\
\hline Faculty $(n=66)$ & $\begin{array}{l}\text { Male }=64 \% \\
\text { Female }=36 \%\end{array}$ & $\begin{array}{l}\text { Albanian }(n=1) \\
\text { American }(n=18) \\
\text { Australian }(n=2) \\
\text { British }(n=5) \\
\text { Bulgarian }(n=2) \\
\text { Canadian }(n=3) \\
\text { Egyptian }(n=1) \\
\text { Indian }(n=4) \\
\text { Iranian }(n=1) \\
\text { Maldivian }(n=1) \\
\text { Moroccan }(n=1) \\
\text { Nigerian }(n=1) \\
\text { Pakistani }(n=3) \\
\text { Russian }(n=1) \\
\text { Sudanese }(n=5) \\
\text { Syrian }(n=3) \\
\text { Tunisian }(n=4) \\
\text { Turkish }(n=7) \\
\text { Ukrainian }(n=1) \\
\text { Yemini }(n=2)\end{array}$ & $\begin{array}{l}\text { Under } 30 \text { years: } 3 \% \\
31-40 \text { years: } 45 \% \\
40+\text { years: } 52 \%\end{array}$ \\
\hline Arab Students $(\mathrm{n}=527)$ & $\begin{array}{l}\text { Male }=24 \% \\
\text { Female }=76 \%\end{array}$ & $\begin{array}{l}\text { Gulf Arab }(n=383) \\
\text { Non-Gulf }(n=144)\end{array}$ & $\begin{array}{l}\text { 15-20 years: } 65 \% \\
21-30 \text { years: } 32 \% \\
31+\text { years: } 3 \%\end{array}$ \\
\hline
\end{tabular}

In the second stage, qualitative data was collected through individual interviews with 10 faculty members and 14 students. Table 4 provides details of the faculty and the students that were interviewed for qualitative data collection.

\section{Table 4}

Qualitative Data Collection: Demographics

\begin{tabular}{llll}
\hline Participants & Gender & Nationality & Age \\
\hline \multirow{3}{*}{ Faculty $(\mathrm{n}=10)$} & & American $(\mathrm{n}=3)$ & \\
& Male $=73 \%$ & British $(\mathrm{n}=2)$ & Under 30 years: \\
& Female $=27 \%$ & Bulgarian $(\mathrm{n}=1)$ & $31-40$ years: \\
& & Maldivian $(\mathrm{n}=1)$ & $40+$ years: \\
& & Sudanese $(\mathrm{n}=1)$ & \\
& & Turkish $(\mathrm{n}=1)$ & \\
Arab Students $(\mathrm{n}=14)$ & Yemeni $(\mathrm{n}=1)$ & $15-20$ years: \\
& Male $=73 \%$ & Gulf Arab $(\mathrm{n}=9)$ & $21-30$ years: \\
& Female $=27 \%$ & Non-Gulf $(\mathrm{n}=5)$ & $31+$ years: \\
\hline
\end{tabular}




\section{Data Collection Strategies}

Sequential explanatory mixed methods was chosen as a research design for this study. According to Creswell et al. (2006), this research design is comprised of two distinct phases: Quantitative and qualitative. Data collected during the quantitative phase is used as a baseline for further investigation in the qualitative stage. Both quantitative and qualitative data collection methods have their strengths and weaknesses. However, considering the limitations of the quantitative and the qualitative stages in understanding multifaceted human behaviors, Miles and Huberman (1994) suggest combining the two data collection methods for detailed exploration of the participant's opinions and beliefs. Following this suggestion, the current study used a mixed methodology to understand faculty and student views about effective teacher characteristics. Two separate questionnaires were used for quantitative and qualitative data collection (see Appendices $1 \& 2)$.

In the first stage, a bilingual survey (English and Arabic) was used to collect quantitative data from the students and the faculty in the program. The instructions on the survey (in both English and Arabic) were adjusted for the students and the faculty when collecting data. However, there were no changes made to the items. The data was collected electronically using Qualtrics.

The researchers visited classrooms and used a brief PowerPoint (PPT) to inform the students of the significance and the importance of the research before asking them to take the survey. It was hoped that this would increase participant motivation to participate in the study and complete the survey in full. The same PPT was used for faculty orientation before data collection. Student participants were selected for being (a) Arabic speaking students and (b) currently enrolled in any of the language courses. On the other hand, all the English language-teaching faculty in the program were invited through group emails and internal memos to take the survey.

The survey consisted of six demographic items related to teacher characteristics: teacher's gender, English accent, teaching method, relationship with students, nationality, and age. Although all six items were borrowed from the Weinstein et al. (2004) study, their wording was modified to adjust to the context of this study. For instance, the items were originally discussed in general and their significance was elaborated on to encourage teachers to prepare them for culturally different students; however, our study used them in the context of language teaching and investigated the views of the students and the faculty in an English language teaching program.

The questionnaire used a slider (from 0 to $100 ; 0$ being no difference and 100 being a huge difference) where participants were asked to drag the slider to record their responses (see Appendix 1). The survey and interview were first piloted with forty-two students and eight faculty to measure their validity and reliability. The purpose was to see if the instruments actually measured the intended research concept and whether they needed any modifications. Following the results from the pilot testing, slight adjustments were made to the survey and interview questions to increase clarity in instructions and item wording to establish the content validity and the construct reliability of the instruments. Data from the survey was used to answer the first research question that aimed to find out which teacher characteristics were valued the most by the students and the faculty.

In the second stage, qualitative data were collected from a convenience sample through individual semi-structured interviews with the faculty and the students to record their in-depth views about the findings from the quantitative stage as well as suggestions to fill the gap in the expectations of the faculty and the students about the most valued teacher characteristics in English language classrooms. Two guidelines were followed for the selection of the faculty for interviews: (1) being full time lecturers; and (2) having at least 3 years of teaching experience in the Gulf. 
These selection criteria allowed the researchers to interview faculty that had a good understanding of the student culture and learning needs and were able to give their opinion about them. In addition, students were selected for this stage if they (1) were Arab students, (2) were currently enrolled in any course at the program, (3) had participated in the quantitative stage, and (4) had intermediate English language proficiency so as to facilitate clear communication. Students were invited for interviews with the help of their instructors who either asked for volunteers from their classes or sent group emails to their current and former students.

The interviews were audiotaped using two electronic devices provided the participants gave their consent. In addition to the recordings, the researchers took extensive notes to increase information availability. At the beginning of the interview, participants were informed of the purpose of the research through a PowerPoint that contained information about the purpose of the research and its aims and a brief summary of the results from the quantitative stage. To increase participant information and data availability, the participants were asked to take the survey questionnaire again and then explain their responses. This was followed by their responses to the findings from the quantitative stage through a comparison between their new responses and survey results. In brief, through a semi-structured interview questionnaire (Appendix B), participants were asked to respond to the quantitative data analysis, suggest if the results aligned with their everyday observations, comment on the implications of the findings, and recommend ways to align facultystudent expectations.

\section{Research Findings}

\section{Quantitative Data Analysis}

Since one of the purposes of the study was to investigate faculty-student expectations of teacher characteristics and to see if any differences exist in their expectations, a test was necessary to measure the differences in the means of the responses of the two groups. A Shapiro Wilk test showed that the data collected through the survey questionnaire was not normally distributed, thus a Mann Whitney test was considered appropriate for the evaluation of differences in the means.

\section{Table 5}

Mann Whitney U Test Results

\begin{tabular}{lccc}
\hline Item & $\begin{array}{c}\text { Mann Whitney } \\
\text { U test result }\end{array}$ & Mean & $\begin{array}{c}\text { Mean Difference } \\
\text { (Cohen's d) }\end{array}$ \\
\hline Accent of the faculty & .000 & $\begin{array}{l}\text { Students: 73.3852 } \\
\text { Teachers: 52.4478 }\end{array}$ & 0.7231 \\
Gender of the instructor & .024 & $\begin{array}{l}\text { Students: 46.7116 } \\
\text { Teacher: 34.8806 }\end{array}$ & 0.3535 \\
Nationality of the instructor & .013 & $\begin{array}{l}\text { Student: 46.2600 } \\
\text { Teacher: 33.4030 }\end{array}$ & 0.3675 \\
\end{tabular}


As can be seen in Table 5, faculty-student expectations on three out of the six given items were statistically different. The differences in means were calculated using Cohen's d effect size calculation. The mean difference between students and faculty on accent of the faculty leaned towards a larger effect size; however, this difference was between small and medium on gender and nationality of the instructor. It should also be observed that student means were higher than faculty on all three items.

Table 6 further displays the findings from the survey. Faculty-student responses on the six items related to teacher characteristics are distributed into three rows depending upon the significance given by the participants. The first row shows the characteristics that were considered highly important by the students and the faculty. Students awarded high importance to teachers' English accent, teaching methodology and the ability to develop a good relationship with their students. On the other hand, faculty gave more importance to the teaching method and relationship building capability of an instructor.

Table 6

Quantitative Data Analysis: Importance Given to Teacher Characteristics

$\begin{array}{lll}\text { Score Range } & \text { Student Expectations } & \text { Teacher Expectations } \\ \text { (Responses: 366) } & \text { Responses (65) }\end{array}$

\begin{tabular}{|c|c|c|}
\hline High End (66\% and higher) & 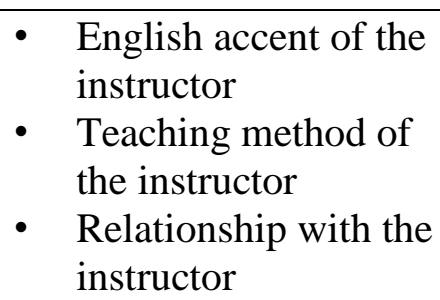 & $\begin{array}{l}\text { - Teaching method of } \\
\text { the instructor } \\
\text { - Relationship with the } \\
\text { instructor }\end{array}$ \\
\hline $\begin{array}{l}\text { Moderate } \\
(33 \%-66 \%)\end{array}$ & $\begin{array}{l}\text { - Gender of the } \\
\text { instructor } \\
\text { - Nationality of the } \\
\text { instructor }\end{array}$ & $\begin{array}{l}\text { - Gender of the } \\
\text { instructor } \\
\text { - English accent of the } \\
\text { instructor }\end{array}$ \\
\hline $\begin{array}{l}\text { Low } \\
\text { ( } 33 \% \text { and lower) }\end{array}$ & - Age of the instructor & $\begin{array}{l}\text { - Nationality of the } \\
\text { instructor } \\
\text { - Age of the instructor }\end{array}$ \\
\hline
\end{tabular}

The second and the third rows contain the characteristics that are considered moderately important by the students and the faculty. Students reported that the gender and the nationality of the instructor were second in importance to them; whereas, faculty considered gender and English accent to be the second most valuable characteristics. The last row presents the characteristics that are given little importance by the students and the faculty. To the faculty, nationality and age of an instructor are the least important. The students also suggested that the age of the instructor does not make any difference to them.

As shown in Table 6, faculty-student preferences for highly valued teacher characteristics did not match only on the English accent of the instructor. Similarly, for the second most preferred characteristic on the list, both agreed on the gender of the instructor but disagreed on nationality and the English accent of the instructor. For the last category, there was disagreement on the 
nationality of the instructor, but both agreed that the age of the instructor is the least important factor for successful language teaching and learning in an EFL classroom.

\section{Qualitative Data Analysis}

The results from the quantitative stage were further explained and elaborated on during individual interviews with the faculty and the students. This helped answer the second and the third research questions, which focused on the differences in the expectations of the participants and the implications of these differences for the teaching and learning process.

All the data were transcribed for initial review by the researchers. Based upon the emergence of certain descriptors and participant statements, a key word coding approach was employed followed by the development of descriptive categories which helped understand why certain teacher characteristics were categorized by the participants in particular ways. Table 7 follows the format of Table 6 in displaying the results of the qualitative stage. As can be seen in the table, both faculty and students considered teaching methodology and relationship development as the most important qualities of an effective teacher. Similarly, the other four characteristics (a teacher's English accent, gender, nationality and age) were second most valuable to faculty participants. However, the students agreed with the faculty only on the accent of the instructor and categorized nationality, gender and age of an instructor as the least valuable characteristics.

\section{Table 7}

Qualitative Data Analysis

\begin{tabular}{|c|c|c|}
\hline Score Range & Student Expectations & Teacher Expectations \\
\hline $\begin{array}{l}\text { High importance } \\
\text { (66\% and higher) }\end{array}$ & $\begin{array}{c}\text { - } \quad \text { Teaching methodology } \\
(76 \%) \\
\text { - } \quad \text { Relationship with the } \\
\text { instructor }(72.85 \%)\end{array}$ & $\begin{array}{c}\text { - Teaching methodology } \\
(93.64 \%) \\
\text { - Relationship with the } \\
\text { instructor }(90 \%)\end{array}$ \\
\hline $\begin{array}{l}\text { Moderate importance } \\
(33 \%-65 \%)\end{array}$ & - Accent (57.50\%) & $\begin{array}{c}\text { - English accent }(51.82 \%) \\
\text { - Gender }(48.18 \%) \\
\text { - Nationality }(47.73 \%) \\
\text { - Age }(43.18 \%)\end{array}$ \\
\hline $\begin{array}{l}\text { Low importance } \\
\text { (32\% and lower) }\end{array}$ & $\begin{array}{l}\text { - Nationality }(31.07 \%) \\
\text { - Gender }(25 \%) \\
\text { - Age }(19.29 \%) \\
\end{array}$ & \\
\hline
\end{tabular}

\section{Discussion}

This study examined teacher characteristics that are valued the most by Arab students and faculty in a language program in a Gulf university. Our results indicate that both students and teachers gave high importance to a teacher's teaching methodology and their ability to build a relationship with their students. This means that a teacher who employs interactive methods of teaching and develops rapport with their students is considered the most effective regardless of their gender, nationality, accent and age. These results are in line with the findings of McKnight 
et al. (2016), McBer (2000) and Sander et al. (2000). For instance, McKnight et al. concluded that their participants from 21 countries considered relationship building as the most valued characteristic of effective instructors. The ability to develop compassionate and trusting relationships with students helps an instructor to not only develop confidence in their students, but also motivate them to participate in the learning process, share their feelings about teaching and learning in general, reduce the dropout rate, and improve the student success ratio. Similarly, McBer argues that the teaching skills of an instructor are an indicator of their effectiveness in class. A teacher can display his/her teaching skills through effective time management, content sharing, lesson planning, designing varied activities that promote critical thinking and student collaboration, and continuous reflection. As teachers employ instructional strategies and put efforts into building connections with their students, they should keep students' context and cultural values in mind to ensure efficiency and effectiveness.

These findings have important implications for instructors, especially those that are novice to this region and/or do not share a similar culture with their students (Syed, 2003) as well as for program administrators and teacher trainers. First of all, they point to the importance of instructional effectiveness that is infused with a cultural understanding so that the educational approaches employed by the English teachers can fully accommodate student needs. This will require them to explore teaching adaptation models that help differentiate instructional strategies to student needs in similar contexts (e.g., Raza, 2018, 2020), investigating student views and perspectives through formal and informal surveys, in-class discussions and interviews (Borg, 2006; DeCapua et al., 2018; Douglas \& Rosvold, 2018; Rubie-Davies et al., 2010), consulting recent research studies that report findings from EFL classrooms (Crabtree, 2010; Kourieos \& Evripidou, 2013; Parker, 2019; Shin \& Jeon, 2018), continuous professional development through in-house trainings, classroom visits and lesson observations (Anderson, 2004; Borg \& Edmett, 2019), and considering language development theories in developing materials and assessments (Darling-Hammond \& Snyder, 2000).

We suggest that English language teachers should not only invest in instructional effectiveness (Coombe, 2020) but also in intercultural competence to enhance an understanding of their students' cultures as well as ways of developing an affinity with them (Klassen et al., 2018; Kustati \& Al-Azmi, 2018; McKnight et al., 2016; Raza, 2020). Contemporary research on CST, especially with a focus on the Gulf context, is a good area for exploration to develop intercultural competence (Crabtree, 2010; Douglas \& Rosvold, 2018; Shin \& Jeon, 2018), resilience and adaptability (Klassen et al., 2018) and with-it-ness (Coombe, 2020). A study that can be beneficial for English teachers in the Gulf context is one conducted by Raza (2019) that proposes developing a teacher-student learning contract to align differing expectations that may be based upon cultural dissimilarity and, consequently, improve intercultural understanding and positive relationships. Raza adds that the trajectory of students' academic success and their social development relies heavily on their connection with their instructor(s) as it promotes an environment that develops upon mutual confidence, trust and respect. Thus sharing expectations and engaging in intercultural dialogues can enhance faculty-student positive relationships and academic performance (Douglas \& Rosvold, 2018).

On the other hand, teacher education and training programs that aim to familiarize preservice and/or new teachers with the local education culture may benefit from these findings by focusing more on developing educational approaches of culturally specific teaching and rapport building with (Arab) students. As Syed (2003) notes 'linguistic and cultural distance between learners and teachers is a serious factor in the Gulf EFL classroom' (p. 339), we argue that teacher 
preparation programs should focus more on developing intercultural competence by signifying the importance of multiculturalism and transnationalism (Shin \& Jeon, 2018) as well as include opportunities for teachers to interact with linguistically and culturally diverse student populations during training periods (Douglas \& Rosvold, 2018; Woofter, 2019). This will be an opportunity for teachers to observe the types of challenges they may face in an actual classroom and brainstorm strategies to address them.

As this study shows that the other four factors (accent, age, nationality and gender) were not considered significant by the participants when measuring teacher effectiveness, another implication of this study at program level is that the findings support equity in hiring opportunities for native and non-native, male and female, young and older, and Western and non-Western English language teachers. Although we observe little discrimination and racism in the Gulf region compared with some other EFL contexts where a preference for native English speaking teachers (NEST) is still visible in job advertisements (Ruecker \& Ives, 2015) and visa policy for foreign English teachers (see Charles, 2019 for a discussion on South Korea), our study reiterates that an English language teacher's employment should rather depend upon their abilities to teach effectively in a harmonious environment. This is in alignment with TESOL International Association's (2006) position statement on the status of and equity for all TESOL professionals: "TESOL strongly opposes discrimination against nonnative English speakers in the field of English language teaching. ... Teaching skills, teaching experience, and professional preparation should be given as much weight as language proficiency".

The study used a mixed methods research design where a bilingual survey was distributed to collect quantitative data which was further explored during individual semi-structured interviews with the participants. Based upon our experience of using this method in this context, we suggest that mixed-methods may produce comparatively more reliable and accurate results as it allows participants to provide detailed responses as well as an opportunity for researchers to understand possible contradictions between quantitative and qualitative results (Creswell et al., 2006). For instance, we observed that the participants, especially students, understood some of the survey items differently from what we intended even though the survey was translated into standard Arabic for convenience. This led to minor differences in the expectations of the students and the faculty about certain teacher characteristics. However, when these differences were further explored during the qualitative stage, we found that students and faculty perceived some of the given items differently. The meanings attached with the terms used in the survey, which were probably based upon participants' previous experiences, led them to choose differing answers. For example, participants' higher preference for English accent of the instructor, gender, and nationality in the quantitative stage was in fact linked to the clarity of speech, fluency and teaching style of the instructor. Since they had the opportunity to explain their responses during the interviews and the results align with existing literature in this area, the results reported in this study as well as the instrument and methodology employed for data collection and analysis do not lose their accuracy and reliability. Thus, as a significant addition of this study to the existing literature on the use of mixed-methods research, we argue that researchers that aim to explore expectations of Arab students or similar topics may include opportunities for the participants to provide detailed responses.

We believe that certain factors might have played a great role in producing the results that we have reported in this paper. Firstly, participant preference for rapport building is in line with general perceptions about the Arab culture. For instance, regardless of the cultural differences, diversity and religious beliefs in the Arab world, the population is generally considered social in 
nature (Sonleitner \& Khelifa, 2005), which is probably why relationship building was considered one of the qualities of an effective teacher. Similarly, the main job of an educator is to facilitate learning through interactive activities and lessons, and language programs in this context already endeavor to provide opportunities for continuous professional development through in-house PDs, conferences, webinars and peer observations. That is why participant preference for a teacher's teaching methodology as a characteristic is not a surprising fact. Lastly, as an attractive destination for employment, the Gulf is linguistically and culturally diverse with Arabic, Urdu, Hindi, Malayalam, Filipino and English as predominant languages (Syed, 2003) and foreigners from numerous countries (Beckett \& Kobaashi, 2020). This multilingualism and multiculturalism is apparent in the society as well as in schools among faculty and students where expatriates mostly outnumber local population. Thus, participants' ranking of accent and nationality as less significant factors is not surprising as they often interact with people having different accents and ethnicities at multiple levels in this context.

\section{Conclusion}

Based upon the CST approach that argues for developing context specific teaching strategies in addition to keeping abreast of general characteristics, our study investigated teacher qualities that are preferred the most by Gulf Arab students and regard them as effective English teachers. We report that the most preferred characteristics of an effective English teacher in the Gulf are their teaching methodology and relationship development with the students. The other four factors, accent, gender, nationality and age, were found to be less significant when measuring teacher effectiveness. English language teachers that are new in the region or face issues in adjusting to the local education culture may benefit from the findings of this study to adapt their teaching strategies to student needs as well as explore ways of developing rapport with their students. Similarly, language program administrators may also focus more on developing their teachers' CST skills and faculty-student harmonious understanding. This can help develop a learning environment that is based upon common understanding and mutual respect. The instrument and methodology used in the study for data collection and its exploration has been successful in understanding student and faculty views about factors that contribute to teacher effectiveness. Our findings report minimal differences in the expectations of the faculty and the students about teacher effectiveness and align with the existing literature on CST research on teacher characteristics.

\section{Further Research}

One of the limitations of this study is that the student population was varied, consisting of degree versus non-degree and junior versus senior students. Further research should investigate the expectations of these students in individual groups to see if any differences exist in their views. Although this paper reports differences between the expectations of the participants, it does not suggest ways to align these inconsistencies. Future research should explore coherent strategies and possibilities to bridge the gap between the expectations of the students and the faculty informed by this study. Another limitation of this research is that the data collection method was specifically developed and used for this study for the first time. Although it has worked well for our study and has produced results that are supported by the existing literature, we cannot guarantee its similar effectiveness in other contexts and situations. To increase the validity and the accuracy of the 
methodology used in this study, additional research is needed to see if this data collection and exploration methodology can be further improved. Lastly, our study used a bilingual survey and a semi-structured interview questionnaire that was piloted and modified before actual data collection; however, we still observed that the participants (both faculty and students) perceived the terms used in the questions differently. Although we were able to explore and record the accurate messages of the participants during the interviews, efforts need to be made to devise questions that use self-explanatory language to avoid confusion.

\section{References}

Adams, B. (2019). The far reaching impact of transformative curriculum. Journal Of Curriculum Studies Research, 1(1), 17-32. https://doi.org/10.46303/jcsr.01.01.2

Alogali, A. (2018). World Englishes: Changing the paradigm of linguistic diversity in global academia. Research in Social Sciences and Technology,3(1), 54-73. https://doi.org/10.46303/ressat.03.01.4

Anderson, L. W. (2004). Increasing teacher effectiveness (2nd ed.). United Nations Educational, Scientific and Cultural Organization (UNESCO).

Arslan, C., \& Tanis, B. M. (2018). Building English vocabulary schema retention using review value calculation for ESL students. Research in Social Sciences and Technology, 3(3), 116-134. https://doi.org/10.46303/ressat.03.03.7

Beckett, G. H., \& Kobayashi, M. (2020). A Meta-study of an Ethnographic Research in a Multicultural and Multilingual Community: Negotiations, Resources, and Dilemmas. American Journal of Qualitative Research, 4(1), 85106. https://doi.org/10.29333/ajqr/8267

Borg, S. (2006). The distinctive characteristics of foreign language teachers. Language Teaching Research, 10(1), 3-31. https://doi.org/10.1191/13621688061r182oa

Borg, S. (2018). Teacher evaluation: Global perspectives and their implications for English language teaching; a literature review. British Council.

Borg, S., \& Edmett, A. (2019). Developing a self-assessment tool for English language teachers. Language Teaching Research, 23(5), 655-679. https://doi.org/10.1177/1362168817752543

Charles, Q. D. (2019). Black teachers of English in South Korea: Constructing identities as a native English speaker and English language teaching professional. TESOL Journal, 10(4). https://doi.org/10.1002/tesj.478

Coombe, C. (2013). 10 characteristics of highly effective EF/SL teachers. SPELT Quarterly, 28(4), 2-11.

Coombe, C. (2020). Quality education begins with teachers: What are the qualities that make a TESOL teacher great? In J. D. M. Agudo (Ed.), Quality in TESOL and teacher education: From a results culture towards a quality culture (pp. 173-184). Routledge.

Crabtree, S. A. (2010). Engaging students from the United Arab Emirates in culturally responsive education. Innovations in Education and Teaching International, 47(1), 85-94. https://doi.org/10.1080/14703290903525929

Creswell, J. W., Ivankova, N. V., \& Stick, S. L. (2006). Using mixed-methods sequential explanatory design: From theory to practice. Field Methods, 18(1), 3-20. https://doi.org/10.1177/1525822X05282260 
Darling-Hammond, L., \& Snyder, J. (2000). Authentic assessment of teaching in context. Teaching \& Teacher Education, 16, 523-545. https://doi.org/10.1016/S0742-051X(00)00015-9

DeCapua, A., \& Marshall, H. W. (2011). Breaking new ground: Teaching students with limited or interrupted formal education in U.S. secondary schools. University of Michigan Press.

DeCapua, A., Marshall, H. W., \& Frydland, N. (2018). The transformational learning journey of a novice ESL teacher of low-literate adults. Journal of Transformative Education, 16(1), 1738. https://doi.org/10.1177/1541344617704645

Donohue, D. (2020). Culture, cognition, and college: How do cultural values and theories of intelligence predict students' intrinsic value for learning?. Journal of Culture and Values in Education. https://doi.org/10.46303/jcve.2020.3

Douglas, S. R., \& Rosvold, M. (2018). Intercultural communicative competence and English for academic purposes: A synthesis review of the scholarly literature. The Canadian Journal of Applied Linguistics, 21(1), 23-42. https://doi.org/10.7202/1050809ar

Glesne, C. (1999). Becoming qualitative researchers: An introduction. Addison Wesley Longman.

Gourneau, B. (2005). Five attitudes of effective teachers: Implications for teacher training. Essays Education, 13, 1-8.

Klassen, R. M., Durksen, T. L., Hashmi, W. A., Kim, L. E., Longden, K., Metsapelto, R. L., Poikkeus, A. M., \& Gyori, J. G. (2018). National context and teacher characteristics: Exploring the critical non-cognitive attributes of novice teachers in four countries. Teaching \& Teacher Education, 72, 64-72. https://doi.org/10.1016/j.tate.2018.03.001

Kourieos, S., \& Evripidou, D. (2013). Students' perceptions of effective EFL teachers in university settings in Cyprus. English Language Teaching, 6(11), 1-16. http://dx.doi.org/10.5539/elt.v6n11p1

Kustati, M., \& Al-Azmi, H. (2018). Pre-Service Teachers' Attitude on ELT Research. Research in Social Sciences and Technology, 3(2), 1-13. https://doi.org/10.46303/ressat.03.02.1

McBer, H. (2000). Research into teacher effectiveness: A model of teacher effectiveness. Department of Education, England. http://dera.ioe.ac.uk/4566/1/RR216.pdf

McKnight, K., Graybeal, J., Yarbro, J., \& Graybeal, L. (2016). The heart of great teaching: Pearson global survey of educator effectiveness. Pearson Publishing. https://www.pearson.com/content/dam/one-dot-com/one-dot-com/global/Files/efficacyand-research/schools/global-survey/reports/RINVN9283_GlobalSurvey_092016.pdf

Metropolitan Center for Urban Education. (2008). Culturally Responsive Classroom Management Strategies.

https://steinhardt.nyu.edu/scmsAdmin/uploads/005/121/Culturally\%20Responsive\%20Cl assroom\%20Mgmt\%20Strat2.pdf

Mezirow, J. (1978). Perspective transformation. Adult Education, 28, 100-110.

Miles, M., \& Huberman, A. M. (1994). Qualitative data analysis. Sage.

Parker, J. (2019). Second language learning and cultural identity. Journal of Curriculum Studies Research, 1(1), 33-42. https://doi.org/10.46303/jcsr.01.01.3

Raza, K. (2018). Adapting teaching strategies to Arab student needs in an EFL classroom. Journal of Ethnic \& Cultural Studies, 5(1), 16-26. http://dx.doi.org/10.29333/ejecs/93

Raza, K. (2019). Student-teacher responsibilities in English studies: An empirical analysis of Arab student and English faculty perceptions. Arab World English Journal, 10(2), 307-322. https://dx.doi.org/10.24093/awej/vol10no2.24 
Raza, K. (2020). Differentiated instruction in English language teaching: Insights into the implementation of Raza's teaching adaptation model in Canadian ESL classrooms. TESL Ontario Contact Magazine, 46(2), 41-50.

Rubie-Davies, C. M., Peterson, E., Irving, E., Widdowson, D., \& Dixon, R. (2010). Expectations of achievement: Student, teacher and parent perceptions. Research in Education, 83, 3653. https://doi.org/10.7227/RIE.83.4

Ruecker, T., \& Ives, L. (2015). White native English speakers needed: The rhetorical construction of privilege in online teacher recruitment spaces. TESOL Quarterly, 49(4), 733-756. https://doi.org/10.1002/tesq.195

Sander, P., Stevenson, K., Coates, D., \& King, M. (2000). University students' expectations of teaching. Studies in Higher Education, 25(3), 309-323. https://doi.org/10.1080/03075070050193433

Shin, J., \& Jeon, M. (2018). Intercultural competence and critical English language teacher education. English Teaching, 73(4), 125-147. https://doi.org/10.15858/engtea.73.4.201812.125

Sonleitner, N., \& Khelifa, M. (2005). Western-educated faculty challenges in a Gulf classroom. Learning and Teaching in Higher Education: Gulf Perspectives, 2(1), 1-21.

Syed, Z. (2003). TESOL in the Gulf: The sociocultural context of English language teaching in the Gulf. TESOL Quarterly, 37(2), 337-341. https://doi.org/10.2307/3588508

Tatar, M., \& Da'as, R. (2012). Teacher's perceptions of their significance towards their students: The effects of cultural background, gender, and school role. Journal of Psychology of Education, 27(3), 351-367. https://doi.org/10.1007/s10212-011-0075-4

TESOL International Association. (2006). Position statement against discrimination of nonnative speakers of English in the field of TESOL. https://www.tesol.org/docs/pdf/5889.pdf

Vural, H. (2019). The relationship of personality traits with English speaking anxiety. Research in Educational Policy and Management, 1(1), 55-74. https://doi.org/10.46303/repam.01.01.5

Weinstein, C. S., Tomlinson-Clarke, S., \& Curran, M. (2004). Toward a conception of culturally responsive classroom management. Journal of Teacher Education, 55(1), 25-38. https://doi.org/10.1177/0022487103259812

Woofter, S. (2019). Book Review: Building Equity: Policies and Practices to Empower All Learners. American Journal of Qualitative Research, 3(1), 136139. https://doi.org/10.29333/ajqr/5815

\section{Notes on Contributors}

Kashif Raza is a Lecturer in English and a Faculty Senator at Qatar University. He has previously taught in the USA and Pakistan and has served on various leadership positions. With academic background in ELT and law, Kashif has been involved in teaching, developing and supervising EAP and ESP law courses, and planning and implementing English education policies at department, college and university levels. His research interests include language policy and planning, educational leadership, expectations and perceptions in education, SLW, and legal English. His forthcoming work is a co-edited book with Christine Coombe and Dudley Reynolds on policy development in TESOL and multilingualism. 
Christine Coombe is an Associate Professor at Dubai Men's College, Higher Colleges of Technology, in the UAE. She has served as the President of TESOL Arabia as well as TESOL International Association from 2011 to 2012 and completed two terms on the TESOL International Board of Directors. Other services to the profession include terms on the British Council Assessment Advisory Board, Chief Examiner of the English B component of the International Baccalaureate and on the Executive Committee for IATEFL. Her recent publication is a co-edited book entitled "Professionalizing Your English Language Teaching" published by Springer.

\section{Appendix A}

\section{Q: The following things positively affect student academic performance:}






\section{Appendix B}

Interview Questionnaire

Focus Group Agenda and Interview Questions on Teacher Characteristics

\section{English Faculty vs. Arab Students}

1. Do these results align with your own observations?

Prompts (if needed):

a. What is consistent with your observations? Can you give an example?

b. What is not consistent with your observations? Can you give an example?

\section{How do you explain or make sense of these results?}

Prompts (if needed):

a. Why do you think these differences show up? Can you give me an example?

b. Do you think there might be any extraneous reasons that might explain the difference (i.e., limitations of the research?)

\section{What do you think the implications of these findings are?}
Prompts (if needed)
a. For faculty?
b. For the universities?
c. For the students? 